\title{
RECORDING AND COMPARING HISTORIC GARDEN ARCHITECTURE. VALUE OF SLAM-BASED RECORDING FOR RESEARCH ON CULTURAL LANDSCAPES IN CONNECTION WITH HERITAGE CONSERVATION
}

\author{
Mona Hess ${ }^{1}$, Carla Ferreyra ${ }^{2}$ \\ ${ }^{1}$ University of Bamberg, Digital Technologies in Heritage Conservation, Institute of Archaeology, Heritage Sciences and \\ Art History, Germany -mona.hess@uni-bamberg.de \\ ${ }^{2}$ University of Salerno, Department of Civil Engineering, Italy - cferreyra@unisa.it
}

KEY WORDS: 3D digital survey, cultural landscapes inventory, simultaneous localization and mapping (SLAM), Mobile Laser Scanning (MLS), architectural research.

\begin{abstract}
The 3D-SLAM-based recording of historic gardens and architecture with the scope of geometric and quantitative analysis of typologies of garden architecture in the context of a designated cultural landscape will be presented. This will be illustrated by case studies of three baroque gardens of buildings belonging to the Cistercian order.

The 'Centre for Heritage Conservation studies and Technologies' (KDWT) at the University of Bamberg is cooperating with the Cisterscapes project to deliver metric surveys, architectural comparison of the historic gardens as typical feature of the agricultural granges. The survey and research were conducted in autumn 2020 and 2021 in two granges in Franconia (Bavaria, Germany) as well as on the monastery of Ebrach.

For the recording, SLAM technology, was the preference and a GeoSLAM ZEB Horizon was used. It is a solution using the data sequence acquired during motion for estimating the relative poses in real time. The case studies served not only to generate an accurate output to be explored in the Cistercian Cultural Heritage Project, but also as test of the instrumentation to ascertain best practices of the instrument. 3D digital documentation will contribute to the holistic understanding of garden plus architecture ensembles. 3D data analysis will be approached from an art-historical and architectural viewpoint, conclusions shall be drawn from interdisciplinary cooperation. This comparative research will serve to find similarities or differences and establish prototypical elements of these typical elements of Cistercian Cultural Landscape. The 3D records can also be used as basis for future monitoring and development of a new garden care concept taking heritage conservation into account. Heritage, in its many forms, is not only a representation of the past, but a connection or reconnection with a past that is active and alive in the present. It shapes and reshapes people's sense of place, sense of belonging and cultural identities at the local and national level.
\end{abstract}

\section{INTRODUCTION}

\subsection{Cisterscapes Project}

Digital technologies have become a powerful tool for the representation and interpretation of cultural heritage, landscape, and architecture.

The Cistercian landscapes, in particular the Ebrach Monastery and the two granges (Ebracher Hof/ Curiae Ebracensis) of Mainstockheim and Oberschwappach, have represented an interesting scenario in which to implement MLS technology, test the latest updates of SLAM techniques characterized by rapid acquisition of data, and ascertain the best practices of a new instrument. Furthermore it served to test the feasibility for the aim to generate accurate documentation for monitoring as well as infographics to be explored in the project 'Cisterscapes Cistercian Landscapes Connecting Europe, 2019-2021' whose aim is the joint application for the European Heritage Label for Cistercian landscapes in order to point out their high importance in European history.
Our approach to the 3D-SLAM-based recording of historic gardens and architecture with the scope of geometric and quantitative analysis of typologies of garden architecture in the context of a designated cultural landscape will be presented. This will be illustrated by case studies of these three baroque gardens with buildings belonging to the Cistercian order, all built in a similar timespan during the $17-18^{\text {th }}$ century. All three gardens have now undergone a change of use, and some of the original features have partly been reinstalled. Yet, the architectural elements of the historic garden serve as identifying features that describe the progression of uses of the site by its subsequent owners. Therefore, these elements are key markers that document the history of the site within its cultural landscape. The garden conservation is relevant to ensure integrity and authenticity of the properties.

The methodology of data acquisition, processing and dissemination has been implemented with the scope of building knowledge, creating meaning, and making culture accessible to everyone. It will furthermore contribute a digital inventory of the selected landscapes and to the

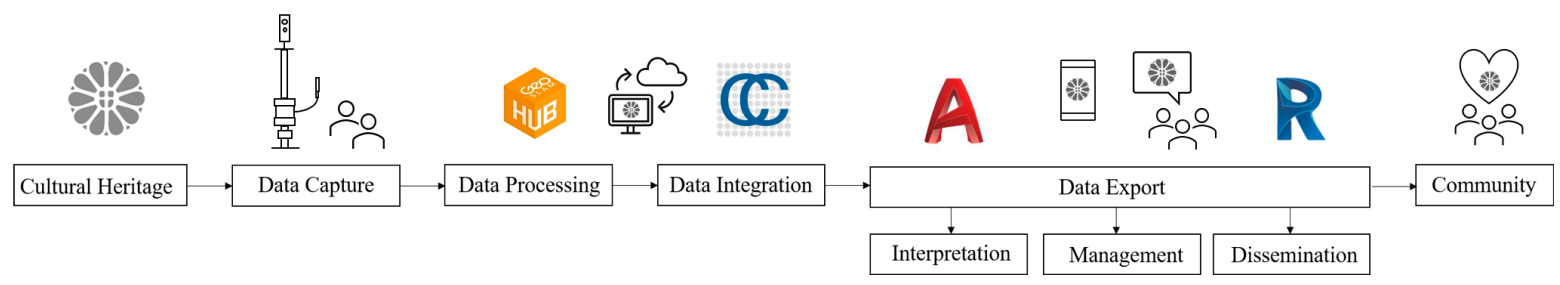

Figure 1: Flowchart of the complete workflow for the contribution to the Cisterscapes Garden Project. 

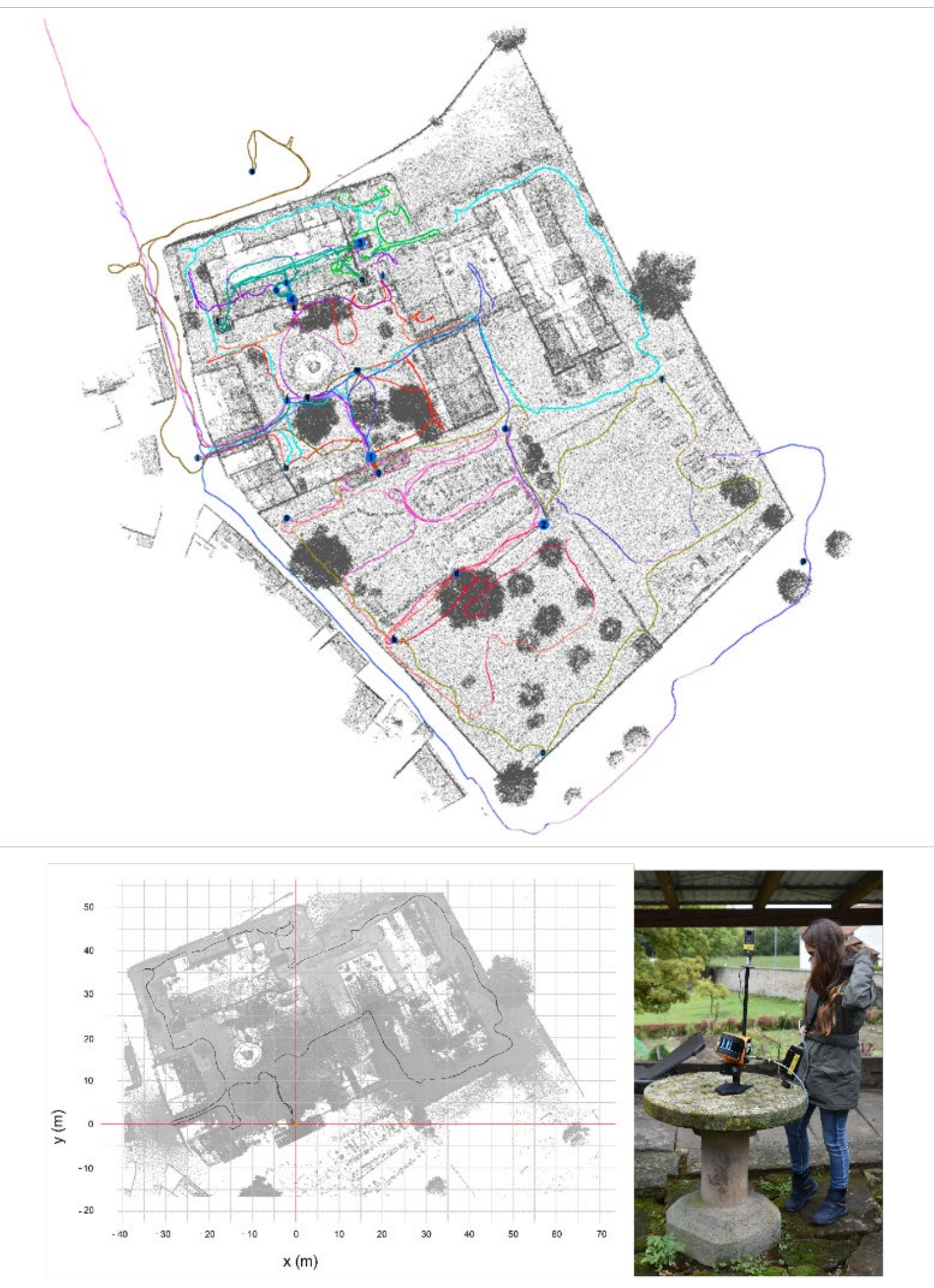

Figure 2: The data capture on the example of Mainstockheim. 12 loops were executed to cover the three different gardens (top) and register them correctly into a joint point cloud (bottom left). Starting points and reference points were defined at regular distances at landscape feature points (blue points on top image and example on top right image). 
possible establishment of the new cultural route of Cistercian Cultural Landscapes (see Figure 1).

\subsection{Historical Cistercian landscape properties}

The Cistercian Order, which developed from the end of the 11th century, experienced its first flowering from Burgundy at the end of the 13th century, during which numerous daughter monasteries were founded in large parts of Europe. The daughter monasteries were often founded in areas, which were sparsely populated. Therefore, the land often had to be reclaimed first. In the process, land use conversions had common characteristic features all over Europe such as a sophisticated hydraulic engineering system, granges (specialised farmsteads) with arable and livestock cattle breeding near the monastery and viticulture. Because of this architectural and horticultural land use and the great continuity, the monasteries had a significant influence on the cultural landscape, which is still visible today and thus forms part of the European identity.

To investigate this aspect and to increase its recognition and awareness, the transnational LEADER cooperation project "Cisterscapes - Cistercian Landscapes connecting Europe" 1 with 17 monastery landscapes in six European countries $^{2}$ was begun. In addition, the district of Bamberg, as transnational coordinator, is aiming to be awarded the 'European Heritage Label' (Denkmalpflege, Gunzelmann and Kastner, 2020).

Reflections on the art-historical and historical values have been presented in the chapters 'Diversity in UnityCistercian Landscapes in Central Europe', 'Between Love of Home and World Heritage - Cultural Landscapes as a Task for both Politicians and Civilians' as well as 'The Abbey and Monastic landscape' (p9 75) in (Denkmalpflege, Gunzelmann and Kastner, 2020).

The 'Centre for Heritage Conservation studies and Technologies' at the University of Bamberg is cooperating with the Cisterscapes project to deliver 3D metric surveys, architectural comparison of the historic gardens as typical feature of the agricultural granges.

The survey and research were conducted in autumn 2020 and spring 2021 in two granges in Franconia (Bavaria, Germany) as well as on the monastery of Ebrach.

1. The first-level daughter monastery of Ebrach was founded in 1136, was one of the richest and most important institutions of its time and included seven granges in the vicinity. Today it is still valued for the outstanding significance of its church architecture. Furthermore, it pertains many of the features of the historic garden, such as sculptures and hydraulic engineering. 3

2. Grange / Ebracher Hof (Curia Ebracensis) in Mainstockheim existed since 1136 but was rebuilt in a more representative architecture at the beginning of the 17th century. From 1727 to 1734, an impressive garden was created. The ensemble is

\footnotetext{
${ }^{1}$ http://cisterscapes.eu/ Cisterscapes project website

https://cisterscapes.geoway.de/map?lon=12.00000\&lat=52.0000 $0 \& z=5$ Database with geolocations of the monasteries under research in the Cisterscapes project.

3 https://cisterscapes.geoway.de/element/76 Monastery landscape Ebrach, Cisterscapes geodatabase.

4 https://www.blfd.bayern.de/ Bavarian state authorities for heritage conservation
}

classified as a historical monument by the Bavarian State Office for the Preservation of Historical Monuments ${ }^{4}$, while the archaeological remains of previous buildings are listed as ground monuments. In 1961 the buildings and garden were acquired by a private family 5

3. Grange / Ebracher Hof (Curia Ebracensis) in Oberschwappach village is a baroque palace, which served to administer the properties of the Cistercian monastery of Ebrach $^{6}$. After secularisation in 1803, the court had different owners and was in poor structural condition when the community of Knetzgau acquired it in 1985 . Today the court houses a museum ${ }^{7}$, a kindergarten and a restaurant.

The architectural elements of the historic garden serve as identifying features that describe the progression of uses of the site by its subsequent owners. Therefore, these elements are key markers that document the history of the site within this cultural landscape. The importance of their conservation is therefore relevant to ensure the integrity and authenticity of the properties. Furthermore, this study will serve as support for the historical research, to analyse the geometry and find similarities and prototypes of the typology of Cultural Landscape; and to contribute as being part of the route of Cistercian Cultural Landscapes.

\section{STATE OF THE ART REVIEW}

\subsection{Digital 3D recording of garden architecture}

3D digital documentation in this research will contribute to the holistic understanding of garden plus architecture ensembles. 3D data analysis will be approached from an art-historical and garden-architectural viewpoint, conclusions shall be drawn from interdisciplinary cooperation, i.e., extraction of open garden areas or enclosed areas - geometric comparison in relation to the cubature of the architecture. This comparative research serves to find similarities or differences and establish prototypical elements of these typical elements of the of Cistercian cultural landscape. The 3D records can also be used as basis for future monitoring and development of a new garden care concept taking heritage conservation into account. This task has been formulated by The Florence Charter (ICOMOS, 1982) and is put into practice by the so-called 'Parkpflegewerk' as instrument in the German heritage conservation authorities.

This project will be embedded in the international context of surveying historic gardens. Other projects exploit 3D data in geospatial applications, such as the field of GIS+database for the management of plants, or in connection with in a Historic Building Information Modelling, for the management of gardens, their maintenance historical forms and planting (Cazzani, Zerbi and Brumana, 2019) and (Malinverni, Chiappini and

\footnotetext{
5 https://seniorenheim-ebracher-hof.de/ Current ownership of the grange in Mainstockheim

6 https://www.knetzgau.de/index.php?id=16356 Current administration of the grange in Oberschwappach

7 http://museen.bistum-

wuerzburg.de/oberschwappach/schloss.htm Current and curation of the grange in Oberschwappach
} 

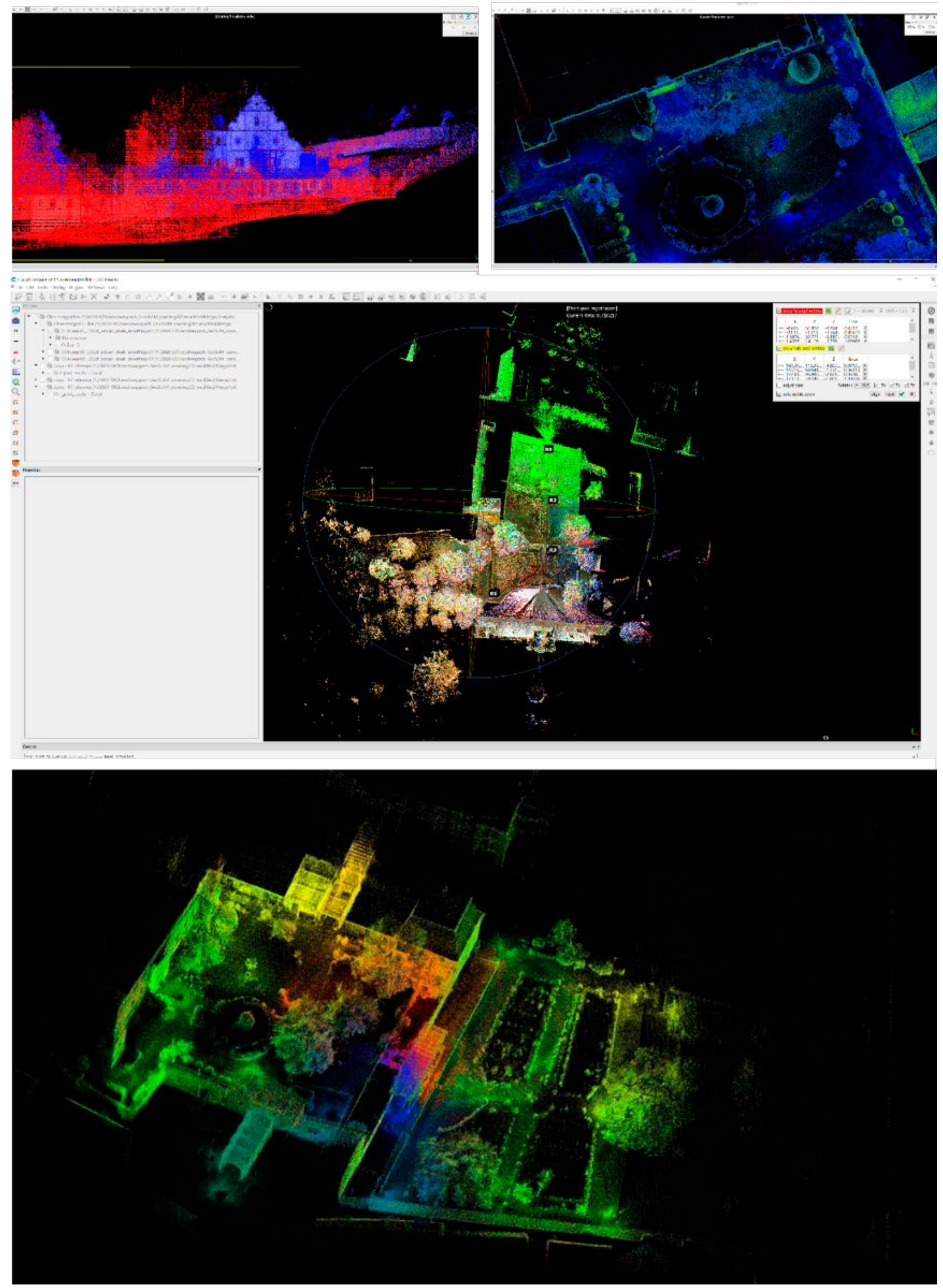

Figure 3: This overview shows steps in the processing workflow in Cloudcompare on the example of Mainstockheim. Top: point cloud to point cloud registration in section and plan, Middle: 3 or more -point-alignment, Bottom: alignment result of pointclouds. 
Pierdicca, 2019). The latest developments in the field of topography are, nowadays, related to the use of low-cost portable LiDAR instruments and to new methodologies such as SLAM which are very promising: probably less accurate but very productive in terms of acquisition and processing time, so they are considered suitable tools for HBIM or inventory (Chiabrando, Lo Turco and Rinaudo, 2017).

\subsection{Mobile Laser Scanning}

SLAM, which stands for Simultaneous Localization and Mapping, is one of the solutions that use the data sequence acquired during motion for estimating the relative poses in real time. SLAM-based MLS has the potential to improve mapping efficiency compared with conventional field measurements (hand survey, tachymetry/total station, 3D TLS), as well as to compensate for the limitations of other laser scanning techniques, such as having to transport the scanner and associated equipment from standpoint to standpoint (Gollob, Ritter and Nothdurft, 2020).

The technology consists of placing a device at an unknown location in an unknown environment and to incrementally build a consistent map of this environment while simultaneously determining its location within this map (Durrant-Whyte and Bailey, 2006). SLAM uses sensors to collects visible data, such as camera imagery, and LiDAR/ 3D Laser scanning, with basic positional data collected using inertial measurement unit (IMU). The devices can include a GNNS sensor to define geolocations on the go along the trajectory. Some of the sensors can be paired with a drone for aerial laserscanning. Together these sensors collect spatial and colorimetric data and build a 3D map of the surrounding environment. By moving its position within the environment, all environmental features will move in relation to the device and the SLAM algorithm can improve its estimate with the new positional information. SLAM-based mobile laser scanners are a convenient inventory instruments due to their mobility and velocity of acquisition. Many research studies have demonstrated this simple and portable device to efficiently collect data during movement, being particularly useful in cases of larger spatial contexts, such as gardens of the Cirstercian Landscapes. In terms of the speed of data collection, previous studies (Liang et al., 2014) have proven that an MLS was several times faster than a terrestrial laser scanner (TLS). In comparison to TLS, MLS reduces the required time on-site. However, the data acquired by MLS is often less accurate than TLS point cloud data, due to the propagation of positioning errors within MLS point cloud data.

\section{METHOD}

\subsection{Data Capture}

For the recording, SLAM technology, has been the preferred approach to data collection with an acceptable noise value $(+/-3 \mathrm{~cm})$ and a GeoSLAM ZEB Horizon was used.

One of the major advantages of applying MLS was rapid data acquisition over the entire site. With a maximum number of 300,000 points/s and up to a range of $100 \mathrm{~m}$, the instrument is suitable to capture the geometry of the surroundings, architecture and its décor as well as planted elements and trees. The case studies served not only to generate an accurate output for further joint exploration and research with the Cistercian Cultural
Heritage Project, but also as test of the instrumentation to ascertain best practices of the instrument.

The Geoslam ZEB Horizon holds a hand-held part (1.49 $\mathrm{kg}$ ) includes a VLP-16 (Velodyne LiDAR Inc., Morgan Hill, CA, USA), a ZEB cam, which is a Firefly 8s camera with $4 \mathrm{k}$ resolution, an inertial measurement unit (IMU), a handle, and a reference plate. The VLP-16 $(0.83 \mathrm{~kg})$ has 16 channels and uses TOF LIDAR technology to measure up to 300,000 points/s in single return mode within a maximum range of $100 \mathrm{~m}$. The distances measured with a continuous wavelength of $903 \mathrm{~nm}$ and a range accuracy of $\pm 3 \mathrm{~cm}$. The FOV of the VLP- 16 is $360^{\circ} \times 30^{\circ}$ with a vertical angular resolution of $2^{\circ}$ and a horizontal angular resolution of $0.1^{\circ}-0.4^{\circ}$, and the internal rotation rate is $5-20 \mathrm{~Hz}$. The VLP-16 is attached to the ZEB Horizon by revolving housing that rotates around an axis orthogonal to the internal rotation axis of the VLP-16. The combination of the internal and external rotation results in an angular FOV of $360^{\circ} \times 270^{\circ}$. The light device has no GNNS/GPS sensor and pre-recorded geolocation points by the Bavarian surveying authorities were picked up by placing the device with the dedicated base plate over these points to include them as reference points for later georeferencing.

The specific SLAM algorithm is characterized by features as post-capture processing, which requires processing 3D-scans after completing the capture. It takes longer than real-time processing, but it also ensures greater reliability in the scan results. Depending on the deadlines, extra processing may not prove to be a big issue but an asset and can efficiently exploit overnight time for processing, to ensure the highest quality data without any extra active time by the operator. Other features are post-scan colorization, which requires a secondary camera (ZEB cam) attached to the device and requires the performing of extra processing steps in the workflow to achieve the desired results. The algorithm has the possibility to import information of colour to assign to each point not only the XYZ coordinates but also RGB data. Importing precise MP4 files to the specific software will colorize the point cloud data after the processing of the scan. The tested MLS tool, ZEB Horizon, with the ability to acquire images to colour the point cloud, suits perfectly for surveying and documentation of architecture and gardens, especially in cultural heritage.

Systems that use SLAM algorithms to generate threedimensional surveys require special attention when planning acquisitions. In fact, more than any other solution, the quality of the raw data based on the SLAM approach depends to a large extent on how the acquisition campaign was carried out. It is important to carefully inspect the site of interest beforehand to identify critical areas and remove any possible obstacles in the way. SLAM systems require intersection of trajectories to ensure proper redistribution of accumulated errors (Fan et al., 2020).

In order to have a strict control of propagation and error compensation, a procedure has been defined that includes a precise survey phase. It was important to respect the walking trajectory in loops, also creating internal loops whilst scanning. When scanning multiple highs, loops must be closed both horizontally and vertically. The longer the scan length without closing a loop, the more absolute error will be created. By closing a loop, repeated measurements are being made of the same area, and thus, the error is minimized. This investigation introduces a set of test datasets related to the documentation of landscape 


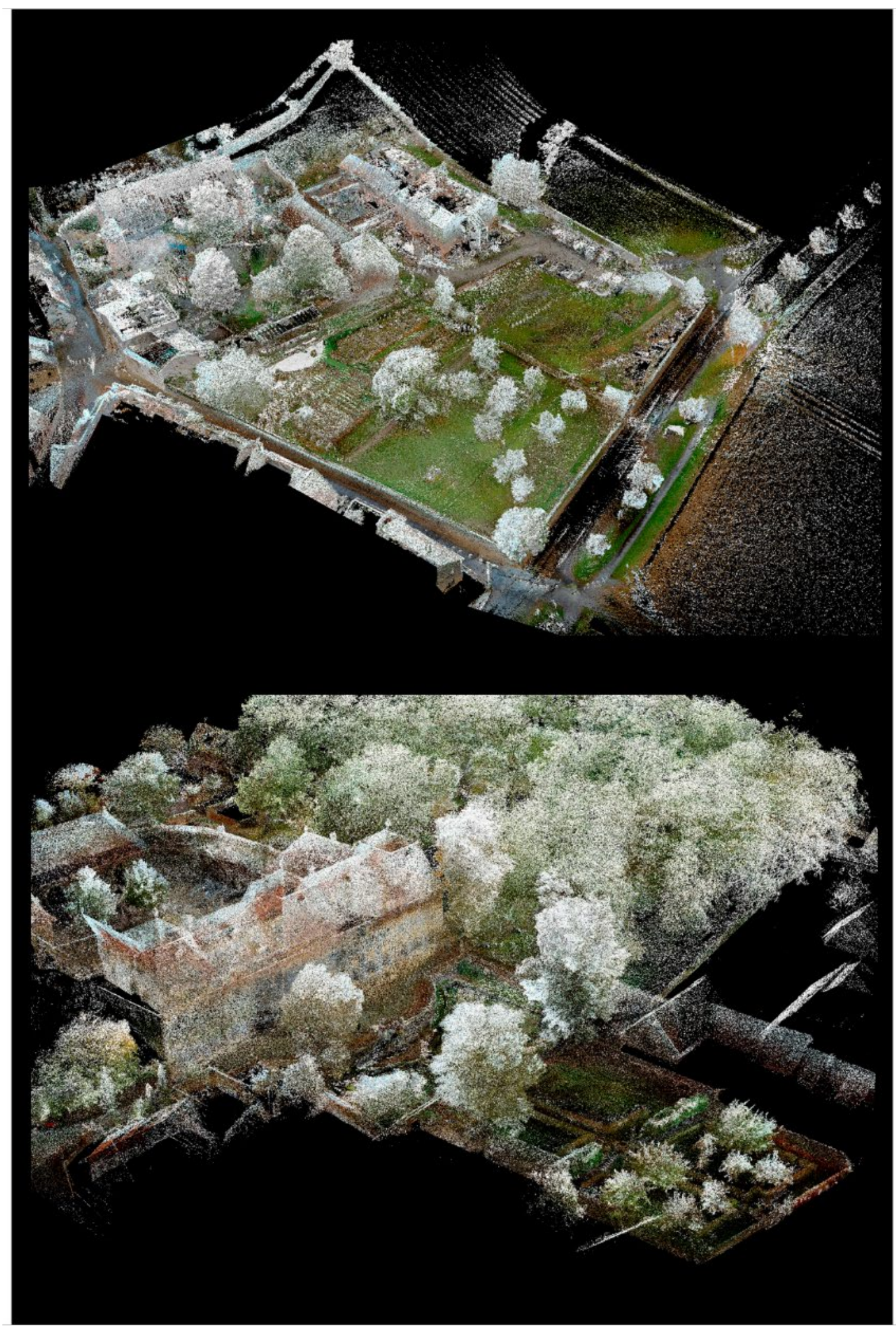

Figure 4: Complete 3D coloured pointcloud of Ebracher Hof in Mainstopheim (top) and Oberschwappach (bottom). The colour comes from the action cam. The botanic features as well as paths and walls are clearly recorded. 
and architecture. The device tested might also face a challenge in large-scale landscapes (see Figure 2).

\subsection{Data Processing}

The data captured was imported in GeoSLAM Hub 6.0.1 software and the data was processed automatically with the SLAM algorithm. A moving time window through the raw data was used for scanner location and to calculate the trajectory of the scanner, based on IMU data and feature detection algorithms. After the first processing, the derived 3D point clouds - exported in LAZ format - were processed in Cloud Compare software to align and merge them. After a first manual transformation for rough alignment between consecutive scans, a finer registration was performed with a traditional iterative closest point (ICP) method. The maximum root mean square (RMS) value in the registration of consecutive scans was approx. $1.95 \mathrm{~cm}$. For Mainstockheim the 10 point clouds were then simply rototranslated in space respecting the reference system of the defined reference scan. Four points were selected in the reference point cloud and in the aligned point cloud to better improve the alignment. For Oberschwappach the 3 point clouds were aligned in reference of the previously defined reference scan.

For the processing workflow see Figure 1 and the processing work in progress see Figure 3

The complete point cloud Ebrach monastery had over $\sim 900$ million points with a density of approximately 400 $\mathrm{pt} / \mathrm{m}$. The recording of the rather large site took 7 hours.

The gardens at Mainstockheim (5 hours) and Oberschwappach (1 hour) were recorded in one day.

The Mainstockheim complete point cloud had over $\sim 723$ million points with a density of approximately $600 \mathrm{pt} / \mathrm{m}$, the weight is $15 \mathrm{~GB}$. It has been sampled in $\mathrm{CC}(0.01)$ resulting in $\sim 366$ million points of $6.5 \mathrm{~GB}$ and $(0.05) \sim 35$ million points of $700 \mathrm{MB}$.

The Oberschwappach complete point cloud had over $\sim 183$ million points with a density of approximately $150 \mathrm{pt} / \mathrm{m}$, the weight is $3.25 \mathrm{~GB}$. It has been sampled in CC resulting in $\sim 40$ million points of $744 \mathrm{MB}$.

The relative accuracy of points obtained by the ZEB Horizon is $\pm 30 \mathrm{~mm}$ in the registered point cloud under normal lighting conditions i.e., daylight. The registered point cloud is given in a local coordinate system, with origin at the start/end position of the walking path.

The complete point clouds can be seen in Figure 4.

\section{RESULTS}

Reliable information has been acquired by MLS to assess the heritage landscape development status of three gardens and to design management plans for its maintenance and conservation. An comparative overview of the 3D processing results in comparison with the historic images can be seen in Figure 5.

Amongst other data products such as $3 \mathrm{D}$ coloured point clouds, accurate orthophotos, plans and sections have been obtained with rigorous metrical recording, which can serve as a basis for the posterior analysis of the typology of the garden - more sections can be extracted where desired.
Furthermore, 3D point clouds can be exploited to be an efficient means of communication of the garden structures to a wider audience. In addition, the aim to promote direct participation of the respective communities as well as dissemination and awareness of intangible historical evidence, a video was disseminated on social networks. ${ }^{8}$ By virtualizing these Cistercian Landscapes and disseminating this project through social media, direct involvement of participants in the community is encouraged. This can support training to young people: scientific methods, techniques, possibilities and to make the heritage accessible to everyone. A tangible outcome of collaboration was the autumn workshop for the 'Restoration of architectural elements in a historic garden' organized by EU Heritage Volunteers, Cisterscapes Project and a stone restoration company of Bamberg, who were using ortho-images from 3D Scans (TLS and SLAM) as basis for survey, condition assessment and damage mapping on a baroque staircase in September $2020^{9}$.

Involving communities in this way helps to make them more aware of the need to protect the site and reinforces the sense of collective belonging to the territory. Heritage, in its many forms, is not only a representation of the past, but a connection or reconnection with a past that is active and alive in the present. It shapes and reshapes people's sense of place, sense of belonging and cultural identities at the local and national level.

\section{CONCLUSION}

One of the major advantages of applying MLS, in the case study GeoSLAM ZEB Horizon, was rapid data acquisition over the entire site. With a maximum number of 300,000 points/s and a maximum range of $100 \mathrm{~m}$, the GeoSLAM ZEB Horizon is suitable to capture the geometry of the surroundings. However, this requires further research. The case studies served not only to generate an accurate output to be explored in the Cistercian Cultural Heritage Project, but as a test of the instrumentation to ascertain the best practices.

The experiences show that this methodology has great potential, which allows a virtual reconstruction of the sites, providing a valid technical and scientific support. It is also an effective means to transform the state of knowledge of a given object, and to communicate the research to a growing audience of potential users. In the field of the digital conservation of cultural heritage we are continuously dealing with new technologies. Even more, with the ultimately trends of the last year, during the pandemic lockdown and travelling remotely, digital documentation becomes a tool for education, enjoyment, and hope for the society.

Future work on this project can include recording of further Curiae Ebracensis - other properties connected to the monastery of Ebrach. A wider-looking approach could indeed be an addendum to the Charter of Florence with the opportunities and benefits of new 3D geospatial imaging and recording technologies enabling rapid recording an their impact on long-term monitoring for historic gardens and cultural landscapes.

\footnotetext{
${ }^{8}$ Youtube Channel of the Digital Technologies in Heritage Conservation, University of Bamberg https://youtu.be/AyPpoGEV8xY
}

${ }^{9}$ Heritage Volunteers EU
https://www.heritagevolunteers.eu/ProjectsByTopics/Traditional
StoneTechniques/RestorationOfArchitecturalElementsInAHistor icGarden? 

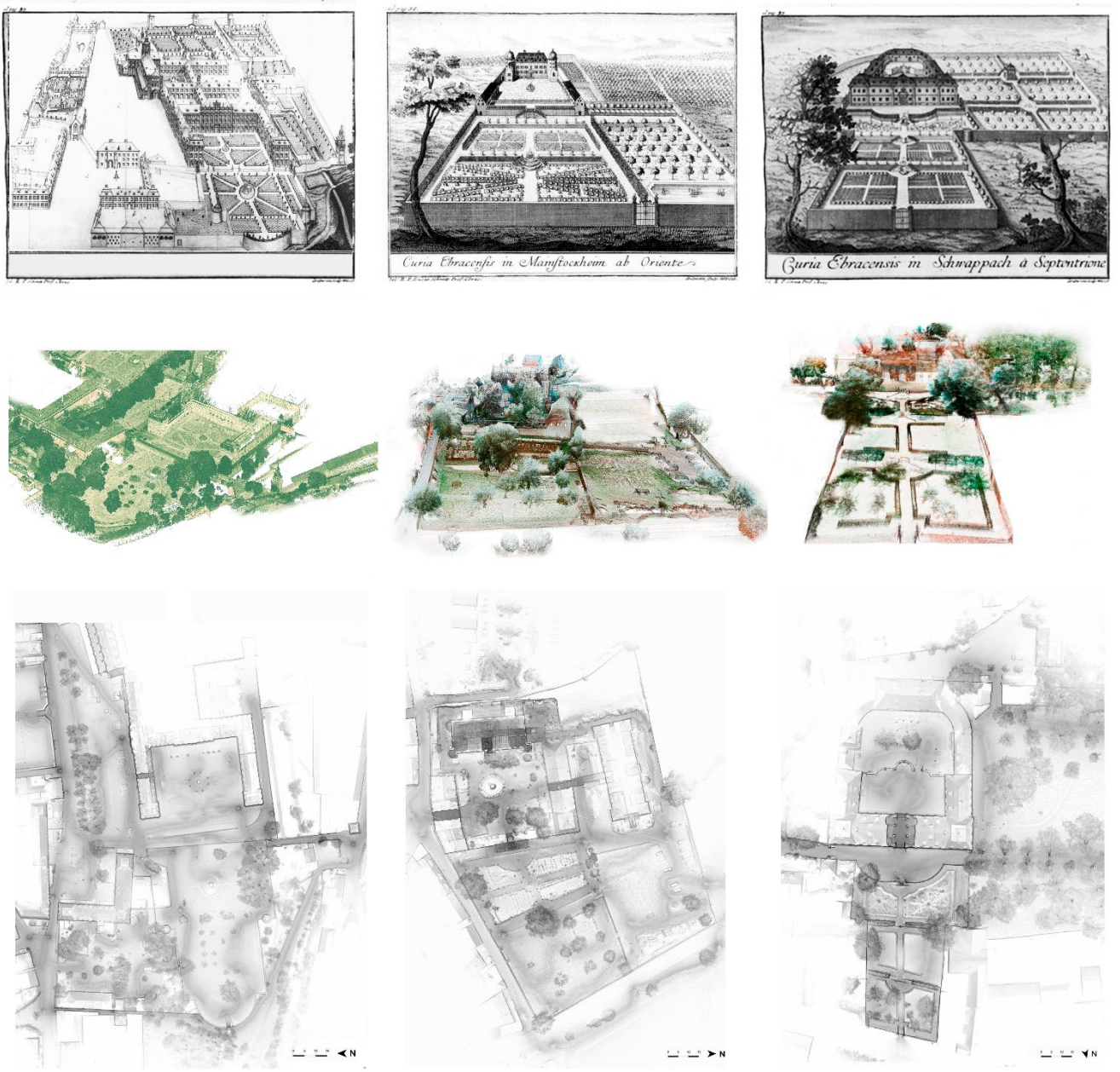

Figure 5:

Matrix of comparison of historic incisions (top) with their 3D SLAM-based recordings shown as coloured 3D point cloud (middle) and greyscale planview (bottom). Monastery of Ebrach (left), Curiae Ebracensis Mainstockheim (middle), Curiae Ebracensis Oberschwappach (right). The historic incisions at the top are from 1803 for Monastery Ebrach by N.A. Berwein (Wiemer, 1999, p. 180), Mainstockheim and Oberschwappach both from 1738 (B.Gutwein after L.Schmidt in Brevis Notitia). The bottom left image of the point cloud of the monastery of Ebrach only shows part of the complete pointcloud that was recorded to facilitate a visual comparison of the main gardens. The main facades' widths are ca. 65-70 metres.

\section{REFERENCES}

Cazzani, A., Zerbi, C. M. and Brumana, R. (2019) 'Management plans and web-GIS software applications as active and dynamic tools to conserve and valorize historic public gardens', in The International Archives of the Photogrammetry, Remote Sensing and Spatial Information Sciences. Copernicus GmbH, pp. 291-298. doi: 10.5194/isprsarchives-XLII-2-W15-291-2019.

Chiabrando, F., Lo Turco, M. and Rinaudo, F. (2017) 'Modeling the decay in an HBIM starting from 3D point clouds. A followed approach for cultural heritage knowledge.', The International Archives of the Photogrammetry, Remote Sensing and Spatial Information Sciences, XLII-2/W5, pp. 605-612. doi: 10.5194/isprs-archives-XLII-2-W5-605-2017.

Denkmalpflege, B. L. für, Gunzelmann, T. and Kastner, B. (2020) Vielfalt in der Einheit - Zisterziensische Klosterlandschaften in Mitteleuropa / Diversity in Unity Cistercian Landscapes in Central Europe: 1.-3. June 2018 in Ebrach/Burgwindheim. 12019th edn. Lindenberg: Fink, Josef.

Durrant-Whyte, H. and Bailey, T. (2006) 'Simultaneous localization and mapping: part I', IEEE Robotics \& Automation Magazine, 13(2), pp. 99-110. doi: 10.1109/MRA.2006.1638022.

Fan, Y. et al. (2020) 'A trunk-based SLAM backend for smartphones with online SLAM in large-scale forest inventories', ISPRS Journal of Photogrammetry and Remote Sensing, 162, pp. 41-49. doi: 10.1016/j.isprsjprs.2020.02.006.

Gollob, C., Ritter, T. and Nothdurft, A. (2020) 'Forest Inventory with Long Range and High-Speed Personal Laser Scanning (PLS) and Simultaneous Localization and Mapping (SLAM) Technology', Remote Sensing, 12(9), p. 1509. doi: 10.3390/rs12091509.

ICOMOS (1982) The Florence Charter on Historic Gardens International Council on Monuments and Sites. Available at: https://www.icomos.org/en/what-we-do/focus/179-articles-enfrancais/ressources/charters-and-standards/158-the-florencecharter (Accessed: 7 July 2021).

Liang, X. et al. (2014) 'Possibilities of a Personal Laser Scanning System for Forest Mapping and Ecosystem Services', p. 21.

Malinverni, E. S., Chiappini, S. and Pierdicca, R. (2019) 'A geodatabase for multisource data management applied to cultural heritage: the case study of Villa Buonaccorsi's historical garden', in The International Archives of the Photogrammetry, Remote Sensing and Spatial Information Sciences. Copernicus GmbH, pp. 771-776. doi: 10.5194/isprsarchives-XLII-2-W11-771-2019.

Wiemer, W. (1999) Die Gärten der Abtei Ebrach. Berlin: Mann. 